\title{
МОЛОДЫЕ ПРОДОЛЬНЫЕ РАСКОЛЫ В МОРФОСТРУКТУРЕ МУРМАНСКОЙ ЗОНЫ РАЗЛОМОВ
}

\section{Никонов А.А.}

Институт физики Земли РАН, Москва, nikonov@ifz.ru

Согласно новейшим исследованиям «Линия Карпинского», известная уже столетие, представляет зону не только древних, но и новейших разрывов. Эта крупная шовная зона на границе Восточно-Европейской (ВЕП) и Западно-Арктической платформ (ЗАП) протягивается на сотни километров, ярко выражена морфоструктурно, на суше ступенями рельефа, долинами и каньонами, а в акватории - ступенями подводного рельефа, и геологически - разломами и приразломными деформациями, а также расколами и трещинами в кристаллических породах $[1,5-7,9,10]$. Резкая морфологическая выраженность Мурманского побережья, крутизна его склонов, дробность рельефа в плане и по высоте, неоднократно отмечались несколькими поколениями исследователей. Также известны многие работы с указанием отражения в рельефе новейших и молодых разломов, вдольбереговых и секущих. Тектоническая зона показана вдоль всего Мурманского побережья на многих специальных картах и схемах мелкого масштаба. Но очень мало публикаций, где рассматриваются конкретные разломы и разрывы с характеристиками кинематики и свидетельствами молодого, поздне- и послеледникового, возраста.

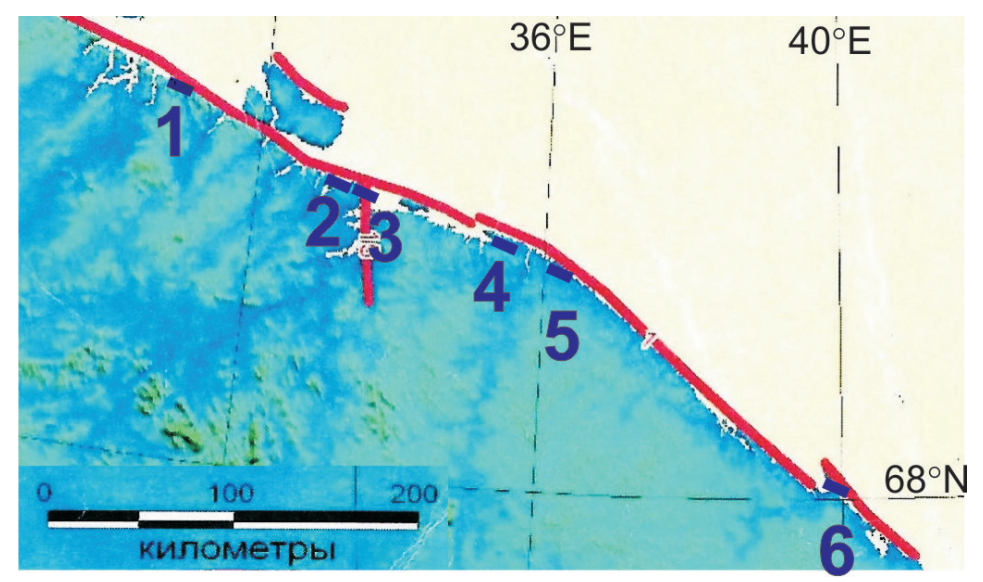

Рис. 1. Мурманская шовная зона («линия Карпинского») и участки выявленных продольных расколов на суше: 1 - губа Долгая, 2 - Ура-Губа, 3 - Кольский залив, 4 - Териберка, 5 - Дальние Зеленцы, 6 - Святой Нос.

По собранным автором материалам (рис. 1) намечаются два типа продольного тектонического раздробления подводной части Мурманского побережья (по геоморфологическим и геофизическим материалам): тип 1-й - на суше платообразное пологое понижений берегового плато в сторону моря с продольными расколам и тип 2-й - вдоль береговых обрывов и под водой ступенчатое, местами с горстами и грабенами, морфоструктура с общим погружением от ВЕП к ЗАП. Ступенчатое блоковое погружение кристаллического фундамента по краю Кольского кратона в сторону Баренцева моря отражено на поперечных профилях в среднем секторе Мурманского побережья [4, 12] (рис. 2) и по морфометрии на участках у о-ва Кильдин, о-ова Олений и у Семиостровья.

В настоящей краткой публикации рассмотрен только первый тип в виде наглядных примеров указанных новообразований, как они фиксировались на фотографиях специалистами и любителями в разные годы. Примеры приведены по секторам Мурманского побережья - западному, среднему и восточному, по несколько на каждом из них. Выбраны тектонические разломы, расколы только продольные по отношению к общему протяжению побережья и со значительными вертикальными перемещениями, которые имеют признаки возникновения в новейшее время и (частично) после дегляциации ледникового покрова. Речь идет не о трещинах, а о расколах, щелях на глубину десятки, местами сотни метров в кристаллических породах докембрия, создающих обращенные в сторону моря ступени на береговых плато и на местных водосборах. 


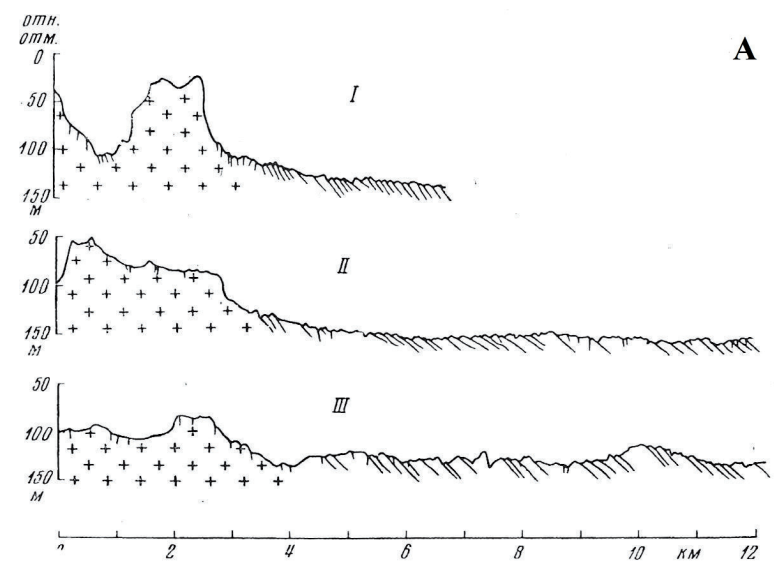

Рис. 2. Схематические разрезы поперек тектонической зоны Карпинского на участках ее среднего сектора по [4] (звукогеолокация: I - на траверзе о. Малый Олений, II - на траверзе о. Харлов, III - на траверзе м. Дворовый) (А) и по [12] (по геолого-геоморфологическим данным: 1 - гранитоиды, 2 - сбросовые уступы, 3 - разрывы растяжения) (Б).
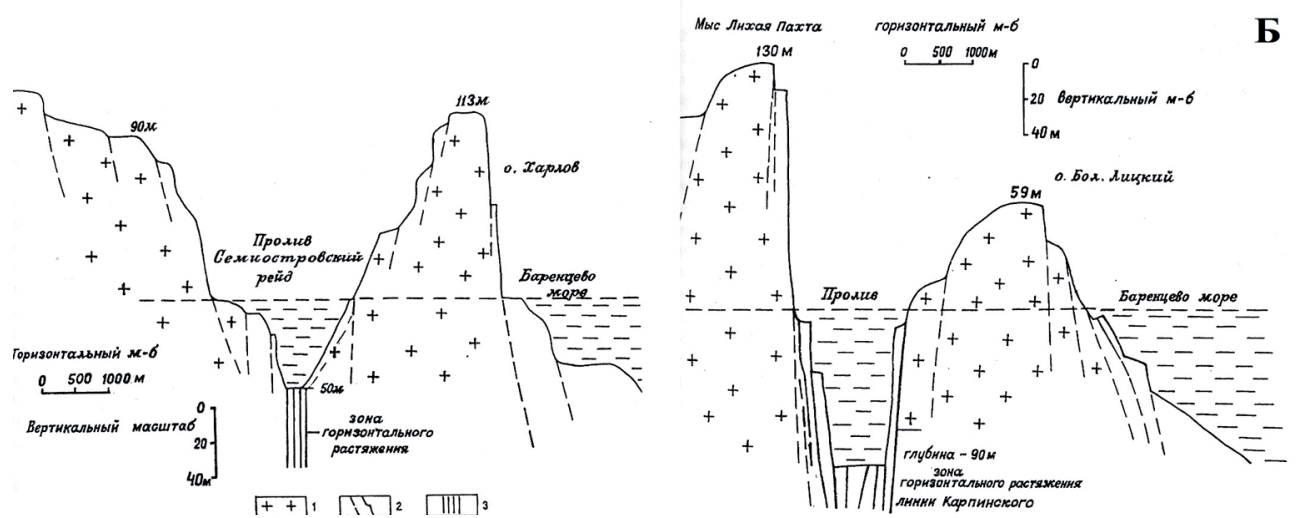

По морфоструктурным признакам на суше выделяются три сектора Мурманского побережья, западный, средний и восточный, расколы в каждом соотносятся с выступами материковой суши к северу у контактов с разломами, косого относительно главной Мурманской зоны простирания. В западном секторе это участок высокого восточного борта губы Долгой северо-западного простирания, заложенной по древнему сдвигу [12] и крупный выступ побережья к северу в виде полуостровов Средний и Рыбачий (рис. 3, 4, 5). В среднем секторе продольные расколы установлены на береговом плато между пос. Териберки (рис. 6А) и Дальние Зеленцы (рис. 6 Б). В восточном секторе Мурманской зоны указанные проявления ярко выражены на длинном выступе к северо-западу п-ова Святой Нос (рис. 7), по бокам ограниченного древними, обновленными разломами со сдвиговой составляющей.

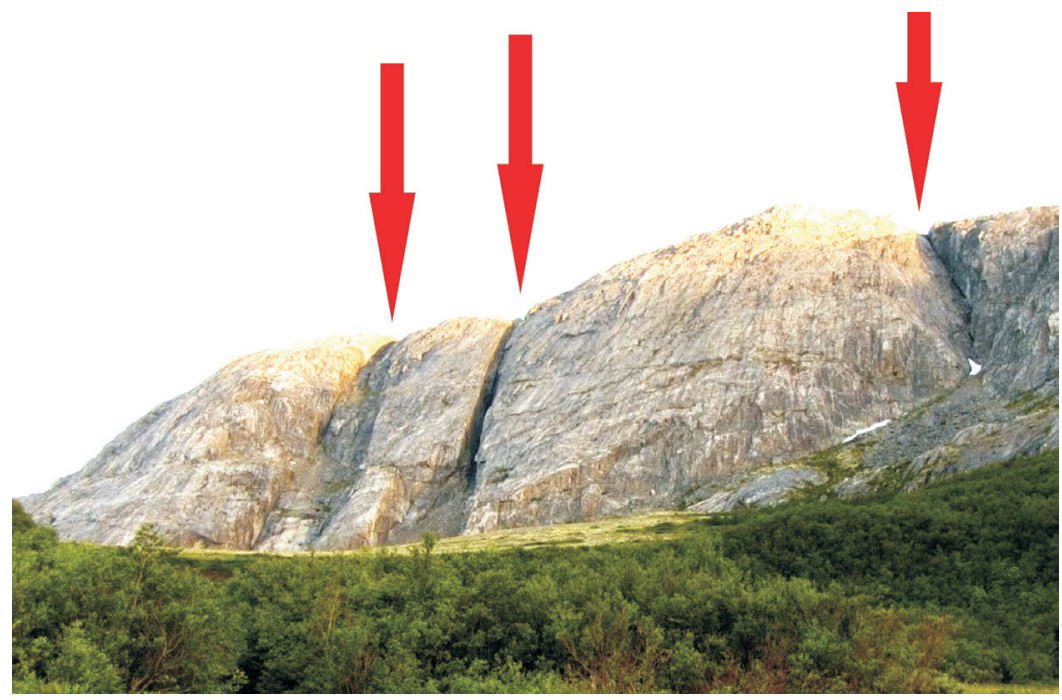

Рис. 3. Северо-восточный борт впадины Долгая Щель с отчетливо морфологически выраженными зонами разломов и новейшим расколом С3 простирания в архейских породах. 

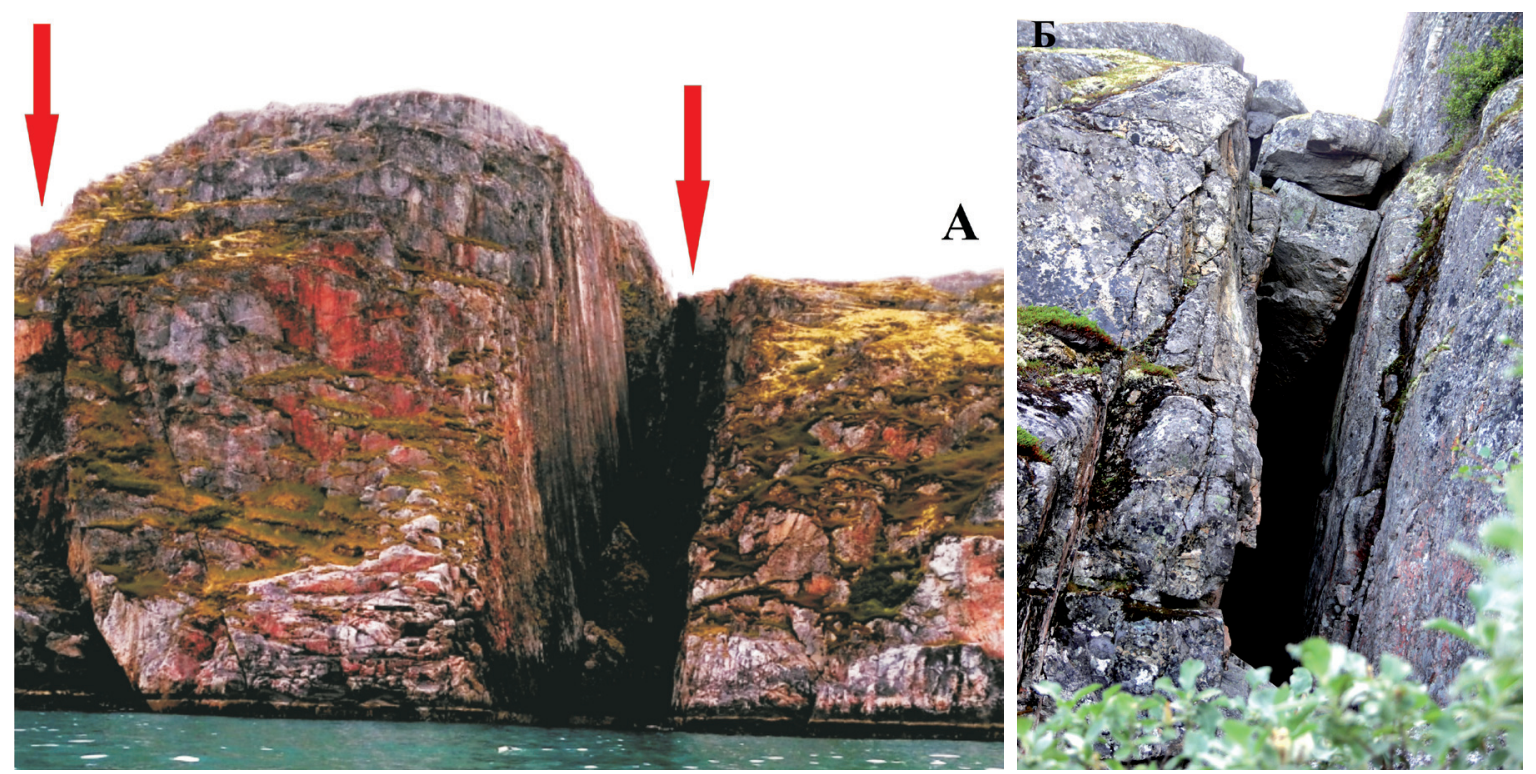

Рис. 4 А, Б. Скальный уступ в северной части Ура-губы, рассеченный молодыми расколами субширотного простирания с вертикальным перемещением бортов (А) и подобный крутопадающий щелевидный раскол по древней разломной зоне (Б). Фото С.В. Егорова.

Практически все демонстрируемые - продольные - расколы скальных массивов поднятого берегового плато демонстрируют признаки возникновения (или обновления) после оставления территории материковым льдом. Выявляются еще, как минимум, две новых закономерности: 1) признаки неотектонической активности в более широкой (в 2-3 раза) подводной полосе той же мегаструктуры и 2) широкое распространение крупных сейсмодеформаций в наземной береговой полосе на всем протяжении Мурманского побережья [1, 3, 8-11]. Собранный в последние десятилетия многими исследователями материал по молодым сейсмонарушениям в пределах Мурманского побережья (его надводной части) удостоверяет в том, что 1) сейсмодеформации разного типа имеют место на всем 500 км протяжении Мурманской зоны, 2) во всех случаях разломы продольные демонстрируют поднятое крыло на материке, а опущенное - в сторону Баренцева моря, 3) во всех трех секторах определенные разными способами сейсмонарушения - сейсмодислокации (первичные разрывы), сейсмогравитационные нарушения и сейсмосмятия в рыхлых слоистых осадках встречаются в возрастном диапазоне от 14 до последних 3-1 тыс. л.н. включительно. При этом ни в одном из фиксированных пунктов по визуальным признакам сила сейсмических воздействий не может оцениваться менее VII-VIII баллов, чаще более. Вдольбереговые узкие грабены ограниченной протяженности не обязательно связывать с поперечным растяжением, они могут быть и структурами пул-а-парт.
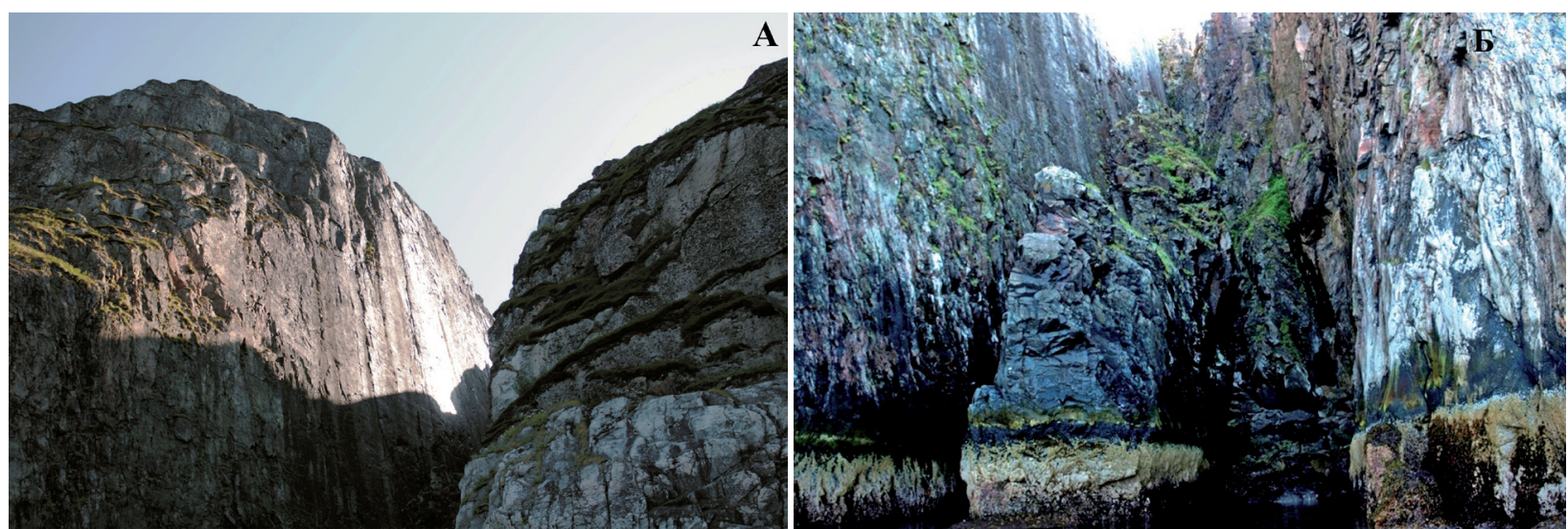

Рис. 5 А, Б. Крупные субширотные новейшие и молодые расколы на севере западного борта Кольского залива по древним разломным зонам. Фото С.В. Егорова. 


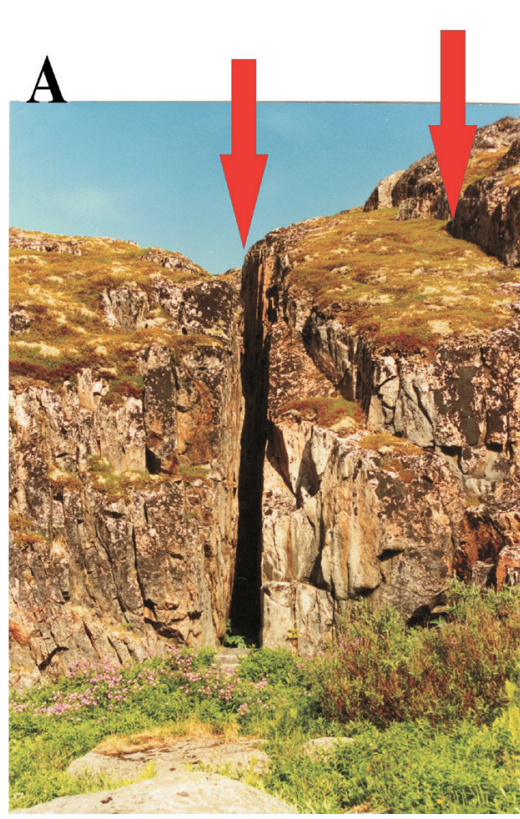

Рис. 6 А. Ступенчатые расколы субширотного простирания на плато Мурманского побережья у пос. Териберка. Любительское фото.

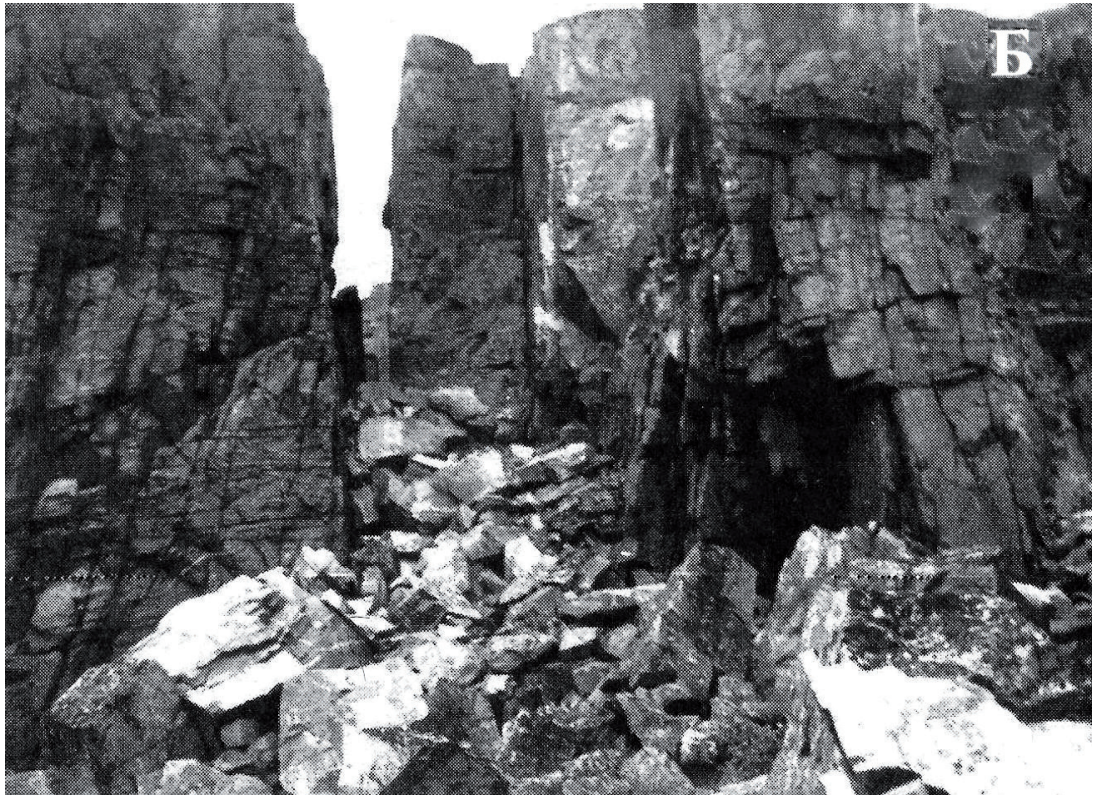

Рис. 6 Б. Тектонический раскол (щель) северо-западного простирания на береговом участке у пос. Дальние Зеленцы. Фото А.Л. Львовой

Помимо масштаба расколов, пока только намечаемого, значение имеет и их количество на каждом, ограниченном, объекте. Их обычно не меньше двух, имеется по четыре-пять и на наиболее протяженном выступе берега в Баренцево море, на Святом Носу - шесть. Это означает, что речь должна идти о явлении системном, показательном с точки зрения закономерностей разрывной тектоники в пределах всей Мурманской зоны. Суммарная видимая амплитуда вертикальных смещений бортов расколов на суше в сторону моря не превышает десяти метров, тогда как высота главных береговых уступов исчисляется десятками метров, так же как и во вдольбереговом подводном про-
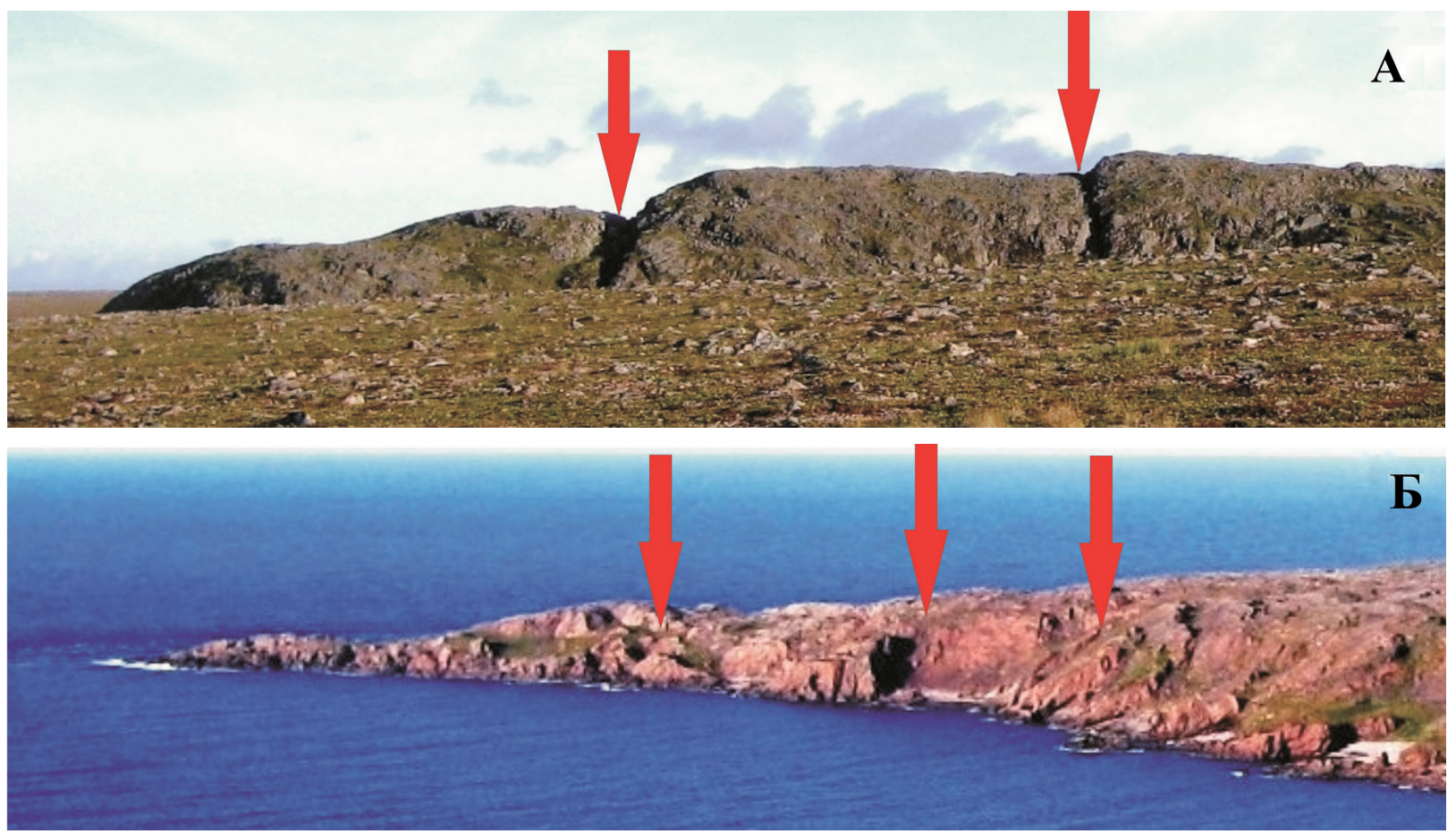

Рис. 7. Субширотные расколы, с вертикальными перемещениям бортов, секущие полуостров Святой Нос в южной, материковой его части (А) и в северной, полуостровной (Б). Вид с запада. Фото Д.С. Зыкова. 
странстве. Соответственно именно они маркируют осевую часть тектонической зоны «Линия Карпинского». Получается, что рассматриваемые продольные расколы на суше - это всего лишь оперяющие разломы, но по-своему, очень показательные и более доступные для дальнейшего изучения. В свете представленных фактов отсутствие Мурманской зоны 500-километровой длины на новой карте активных разломов Евразии [2] нельзя признать действительным.

Автор признателен Л.Д. Флейфель за всестороннюю помощь при подготовке статьи.

\section{Литература}

1. Авенариус И.Г. Морфоструктурный анализ при изучении культурного и природного наследия ЗападноАрктического региона России. Паульсен, 2007. 197 с.

2. Бачманов Д.М., Кожурин А.И., Трифонов В.Г. База данных активных разломов Финляндии // Геодинамика и тектонофизика. 2017. Т. 8. № 4. С. 711-736.

3. Верзилин Н.Н., Бобков А.А., Кулькова М.А., Нестеров Е.М., Нестерова Л.А., Мадянова Н.П. О возрасте и образовании современного расчлененного рельефа севера Кольского п-ова // Вестник С-Пб. Ун-та. Сер. 7: Геол. Геогр. 2013. Т. 2. С. 79-93.

4. Гуревич В.И., Гимпельсон И.А., Макиевский С.И. К установлению «Линии Карпинского» (по данным звуковой геологации) // ДАН СССР. 1972. Т. 205. № 2. С. 422-423.

5. Зыков Д.С. Морфоструктура области сочленения Восточно-Европейской и Западно-Арктической платформ как отражение горизонтальной компоненты подвижности земной коры // Геоморфология. 2014. № 3. С. $62-73$.

6. Зыков Д.С., Полещук А.В., Никонов А.А. Морфоструктура пограничной зоны между Балтийским щитом и Западно-Арктической платформой как отражение взаимодействия геодинамических систем // Геоморфология. 2017. № 2. С. 79-89.

7. Митяев М.В. Мурманское побережье (геолого-геоморфологические и климатические особенности, современные геологические процессы). Апатиты. 2014. 226 с.

8. Николаева С.Б. Свидетельства сейсмических событий на побережье Мурмана в позднеледниковье и голоцене) // Изв. Русск. Географ. общ-ва. 2013. Т. 145. Вып. 4. С. 53-65.

9. Никонов А.А., Зыков Д.С., Николаева С.Б., Шварев С.В. Шовная зона «Линия Карпинского» - Трольфьорд на севере Европы как активный тектонически и сейсмически сейсмолинеамент высшего порядка // Проблемы тектоники и геодинамики земной коры и мантии. Матер. L Тектонич. совещания. T. 2. М. ГЕОС. 2018. С. 52-55.

10. Никонов А.А., Николаева С.Б. Линеамент Карпинского на границе Фенноскандинавского кристаллического щита и Баренцевой плиты как активная тектоническая и сейсмическая зона // Комплексные исследования природы Шпицбергена и шельфа. Матер. Междунар. научной конфер. Вып. 12. М.: ГЕОС, 2014. C. 232-237.

11. Никонов А.А., Шварев С.В., Николаева С.Б. Мурманское побережье - крупнейшая в Российской Арктике сейсмогенерирующая зона: новейшие разработки // Природные ресурсы и комплексное освоение прибрежный районов Арктической зоны. Сб. научных трудов. Отв. ред. В.И. Павленко. Архангельск. 2015. С. 34-40.

12. Чувардинский В.Г. Неотектоника восточной части Балтийского щита. Апатиты. 2000. 288 c. 